\title{
Workplace Environment and Employee Performance in Fort Portal Referral Hospital, Uganda
}

\author{
David Agaba ${ }^{1}$, Cyprian Ssebagala², Timbirimu Micheal ${ }^{3}$, Kiizah, Pastor ${ }^{4}$, \\ Olutayo K. Osunsan ${ }^{5 *}$
}

\begin{abstract}
${ }^{1}$ Faculty of Business and Management, Uganda Martyrs University, Uganda. ${ }^{2}$ Associate Dean, Faculty of Business and Management, Uganda Martyrs University, Uganda. ${ }^{3}$ Lecturer, College of Economics and Management, Kampala International University, Uganda and Uganda Martyrs University- Mbale Branch, Uganda. ${ }^{4}$ Lecturer/Coordinator, Faculty of Business Administration and management, Uganda Martyrs University- Mbale Branch, Uganda. ${ }^{5}$ Lecturer, Department of Business Management, College of Economics and Management, Kampala International University, Uganda.
\end{abstract}

\begin{abstract}
The study sought to explore the effect of workplace environment on the performance of employees among Health Care Providers with focus on Fort Portal Regional Referral Hospital. The Specific objectives for this study were; to establish the relationships between physical environment, psychosocial environment and work life balance respectively on employee performance among Health Care Providers at Fort Portal Referral Hospital. The study used a cross sectional research design where the data on the study variables were collected at the same point in time. The study population involved comprised of 324 Health Care Providers at Fort Portal Regional Referral Hospital in Uganda of which 140 were considered for the study, however 122 responded. They included Administrative staff, Doctors, Nurses, Lab officers and Pharmacists. The study established that there is a statistically significant positive relationship between physical environment and workers' performance $(r=0.218, p<0.05)$; a statistically significant positive relationship between psychosocial environment and workers performance $(r=0.221, p<0.05)$ and; a statistically insignificant relationship between work life balances and workers performance $(r=0.147, p>0.05)$. However, the study found that work environment has a significant effect on employee performance in Fort Portal Regional Referral Hospital $\left(\mathrm{R}^{2}=0.11, \mathrm{p}<0.05\right)$. Recommend were made that management of the hospital should always try to create a conducive workplace environment that aid the performance of work. They should also place a lot of emphasis on the physical and psychosocial environment to improve performance, efficiency, better morale and increased customer satisfaction. This is very much important in the Health Care sector due to the COVID-19 pandemic and the standard operating procedures it calls for. Health Care Providers and management of Fort Portal Referral Hospital are further encouraged to maintain good communication in the workplace that involves workers in the progress and application of healthy and safe workplace practices that balances work and family responsibilities.
\end{abstract}

Keywords: Workplace Environment, Employee Performance, COVID-19, Uganda.

\subsection{INTRODUCTION}

The environment is a person's immediate surrounding which can be manipulated for their existence. Wrongful or inappropriate manipulation presents dangers that make the environments hazardous and undermines the productivity levels of the worker. Consequently, the workplace reflects an environment in which the employees perform their work (1) while an effective workplace is a setting where set outcomes can be realised as expected by the organisation's management $(2,3)$.

Globally, workplace environment plays a vital role in guaranteeing worker's job performance (4) due to the fact that it may influence employee confidence and productivity (5). A Healthy

*Address of Correspondence: Olutayo K. Osunsan, Lecturer, Department of Business Management, College of Economics and Management, Kampala International University, Uganda. E-mail- oosunsan@kiu.ac.ug (Received 14 October 2020; Revised 27 October 2020; Accepted 29 October 2020) 
workplace environment influences the employee in several ways as well as enhancing their performance. Past studies (6) have revealed the link between employees' satisfaction with explicit workplace features such as effective communication, supervisor leadership support, resource availability and accessibility, synergy and goal setting. This is because; those who work under inconvenient circumstances will most probably have low performance and end up with occupational issues such as absenteeism (6).

Auspicious workplace environment assurances the wellbeing of workers and allows them to devote more of themselves to their roles with vigor that may suggest a higher level of performance (7). It is argued that the workplace environment is the most important factor in maintaining employee satisfaction. If not satisfied employees have other opportunities they can explore elsewhere (8) as long as they have the right qualifications and skills.

Organisation efficiency and effectiveness can be created through establishing the wellbeing of employees which increase individual performance. Employees generally have expectation and will expect a workplace environment that will enable them to perform their work optimally (9). Poorly setup workspace, inappropriate furniture, lack of aeriation, unsuitable lighting and excessive distractions adversely affect employee performance (10).

In addition, psychosocial factors i.e. the non-physical aspects of a work setting, such as lack of supervisors' social support and poor working climate can negatively affect workers' performance. An imbalance between workplace environment issues and worker's needs, competence and expectations, is being manifested in different hospitals, prompting diverse reactions. To establish the acceptable standard in work-life balance, the right strategies, programs and action plans have to be put in place. The approach of work-life balance is also now a major consideration in organisations including hospitals as they attempt to stimulate increased performance levels (8).

Fort Portal Regional Referral Hospital is faced with inadequate office space for workers to do their work effectively, noisy environment and delays in payments (11). It is therefore important to find out the impact of working environment on workers' performance. The study sought to establish the effect of workplace environment on employee performance among the Health Care Providers with focus on Fort Portal Regional Referral Hospital. More specifically to: (i) to establish the relationship between physical environment and employee performance, (ii) to examine the relationship between psychosocial environment and employee performance, and (iii)to examine the relationship between work life balance and employee performance.

\subsection{LITERATURE REVIEW}

\subsection{Workplace Environment}

The workplace is characterised as the location in which the employees perform their work while an effective work environment is where results can be achieved to the level of managements expectation $(2,3)$. Workplace environment has been conceptualised by analysing the extent to which employees observe their immediate surroundings as intrinsically and extrinsically satisfying their social needs and thus informing their intention for remaining with organization (12).

A good workplace environment is a rational business decision that is sound and is characterised by mutual respect between management and employees which facilitates employee engagement and results in a highperformance culture that inspires innovation and creativity (5). Organisations seen as a good place to work are more likely to have a competitive advantage because they are better able to attract and retain highly qualified and skilled employees. This is an important consideration in the current constricted labour market due to the challenges of COVID-19. A good workplace environment is likely to yield less employee turnover, lower levels of fraud, improved safety practices, easy attraction and retention of skilled and qualified employees and improved employees' overall wellbeing (13).

The outstanding factors in the physical workplace environment that may influence employees can be divided into several broad areas such as: ambient properties, spatial arrangements and architectural design. Ambient aspects in the office environments, such as sufficient ventilation and can influence employee's perspectives, actions, satisfaction, performance and productivity levels (14).

\subsection{Employee Performance}

Employee's performance is the joint result of exertion, aptitude, and insight of tasks (15). A study (16) referred to employee performance in terms of the quality of work, timeliness of activities and effectiveness of employee work in an organisation. Employee performance is a key multifaceted factor aimed at the attainment of outcomes and has a major association with planned and deliberate objectives of the organization (17). Employee's performance is essential for organizational 
outcomes and overall success (18). Though many things influence the performance of employees; workplace environment factors stand out as one of the key bases of performance (16).

Due to the fact that Health care is labour intensive human resources one of the essential components for effective health care delivery. World Health Reports and a range of other reports find that health worker performance in many lowincome countries including Uganda is sub-optimal (19). Thus, African countries including Uganda, are trying to improve the functioning of healthcare delivery system to ensure that the populations they serve receive timely quality care using qualified and enough human resources (20). In health care, the problem of increasing performance and making the work environment more pleasant has been approached through the introduction of changes in working environment (21).

\subsubsection{Physical Work Environment and Employee Performance}

Physical environment influences how organisation employees are led, co-operate, and perform tasks. Physical environment as a subset of the work environment have directly altered interpersonal connections and thus productivity. This is because the features of a work location, office space or a place of meeting have significance with respect to satisfaction and regarding productivity levels of an organisation's employees (22). Today's workplace is dynamic, diverse, and constantly evolving. The workplace environment is argued to be the most critical factor in keeping an employee satisfied in today's business world (23).

The study (23) specified that physical environment can be categorised as the office layout plan and the office comfort. He also asserted that the physical environment is and should be aimed at achieving the goals of the company. A physical work environment can lead to an employee fitting or not fitting in the workplace. The study by (24) stated that features of the physical work environment help on the functional and aesthetic side in that the décor, and setup of the workplace environment helps enhance the employees experience and facilitate better performance. Several researchers $(5,25)$ conclude that there is a significant effect of Physical Work Environment on Employee Performance and thus ensure productivity of employees (26), Similarly (27) indicates that the work environment plays a significant role in enhancing employee performance in organisations. On the basis the literature the following null hypothesis was stated:
H1: $\quad$ There is no significant relationship between physical environment and employee performance in Fort Portal Referral Hospital, Uganda.

\subsubsection{Psychosocial Environment and Employee Performance}

Psychosocial factors of the workplace environment denote the relations between the employee and the environment and working situations, organizational circumstances, content of the work. It reflects interpersonal and social interactions that may as well as the effect the employee's individual characteristics and those of members of their families as relating to the job and the organisation (28). Consequently, the nature of the psychosocial factors is multifaceted, covering issues relating to the workers, overall environment and nature of work. The psychosocial factor of work environment is one of the most important issues in contemporary and future workplaces due to the fact that it has a significant effect on stress levels and employee overall health (29). The researchers (30) suggest good employee workplace welfare in terms of six key aspects: a realistic workload; a level of personal control over the job position; support from workmates and supervisors; constructive relationships in the workplace; a sensibly clear work role; and a sense influence or control in changes that take place the environment. Individual engagement with the working environment is essential as they influence the ability of the individual regulate and monitor their work and stress levels experienced within the work environment $(29,31)$.

Several studies $(32,33,34,35)$ have confirmed the positive effect of psychosocial environment on employee performance. On the basis the literature the following null hypothesis was stated:

$\mathrm{H} 2$ : $\quad$ There is no significant relationship between psychosocial environment and employee performance in Fort Portal Referral Hospital, Uganda.

\subsubsection{Work Life Balance and Workers Performance}

Work-life balance is a mixture of connections among different areas of one's personal private life and employment/work life, the good and bad in these aspects of life is linked to the balance or imbalance that can affect various levels of employees required roles (36). Work-life balance 
has been defined minimal conflict in the satisfaction and good functioning of an individual's roles at work and at home (37). It is the extent to which an individual is able to concurrently balance and manage the emotional, and behavioural strains of both employment and family obligations (38). According to (8) Work-life balance is defined as "people spending sufficient time at their jobs while also spending adequate time on other pursuits, such as family, friends, and hobbies". It is an indication of the need for all employees to manage their work lives as well as their nonprofessional lives, regardless of their family and domestic obligations (39). The inability of employees to attain balance between the work and private life obligations can have significant negative consequences for both the employee and the organisation (40). The authors (41) explored worklife balance using two items: how successful employee feel about their ability to balance work and personal life, and the level of conflict that arise as a result of trying to balance the two. As a response to the two concerns, a rising number of organisations now offer wide-ranging work-life programs for their employees in an attempt to create an equilibrium in work life balance. Worklife balance initiatives commonly include facilitating activities like flexible hours, constructive teams, physical wellbeing and part-time work opportunities (42).

Review of the literature $(43,44,45)$ provides some evidence for the claim regarding recruitment, other (46) argue there is insufficient evidence to support the notion that work-life practices enhance performance. Other studies (47, 48) suggest that the imbalance of work life balance will lead to adverse and negative effect of the organisations including performance. On the basis the literature the following null hypothesis was stated:

H3: There is no significant relationship between work life balance and employee performance in Fort Portal Referral Hospital, Uganda.

\subsection{METHODOLOGY}

The researcher used a cross sectional research design which is where the data on the study variables is collected at the same point in time. There were 324 Health Care Providers at Fort Portal Referral Hospital in Uganda including Administration, Medical Doctors, Nurses, Lab officers and Pharmacy (11). The table suggested by (49) was used to determine the sample size of 140 respondents of Health Care Providers at Fort Portal Referral Hospital.

Workplace environment was measured using Physical Environment, such as Furniture, Lighting, Ventilation, Noise (50); Psychosocial Environment focused on personal relationships (51); and Work life Balances included Job demands, work load and personal life (52). Employee performance in were measured using Quality of service, Productivity, Timeless (Beating deadlines) and Organisational goals achieved (53 ,54). Reliability was tested and all constructs had their Cronbach alpha values above 0.5; Workers performance (0.812), Physical Environment (0.733), Psychosocial Environment (0.812) and Work life Balances (0.714). This suggests that the questionnaire was highly reliable as suggested by (55).

The questionnaire collect data on the effect of workplace environment on workers performance using scored five Likert scale ranging from 1 for strongly disagree, $2=$ disagree, $3=$ not sure, 4 = agree to 5 for strongly agree. A selection of 1 indicates "strongly disagree" and 5 indicate "strongly agree". Interpretations were based on 4.21-5.00 - Very High, 3.41-4.20 - High level, 2.613.40 - Moderate, 1.81-2.60 - Low, and 1.00-1.80 Very low. Correlations and Multiple regression analysis where used to test null hypothesis and effect regarding the variables.

\subsection{FINDINGS}

\subsection{Response Rate}

Out of a sample of 140 respondents that was identified for the study, only 122 respondents fully participated in the study, through filling and returning the completed questionnaires. This accounted for a response rate of $87.1 \%$. According to (55) for a study to be considered reliable and valid, the response rate should be $70 \%$ or above.

\subsection{Demographics of Respondents}

Most respondents (60.7\%) were Nurses, medical doctors (18.0\%), administrative staff (16.4\%) laboratory officers (3.3\%) and Pharmacist (1.6\%). The majority $(69.7 \%)$ was females while $30.3 \%$ respondents were males. The majority the respondents (41.0\%) worked for the Hospital between 2 and 5 years, between 6 and 10 years $(25.4 \%)$ and above 10 years (18.9\%). The majority (49.2\%) of the medical workers in Fort Portal Regional Referral Hospital were Certificate and Diplomas, followed by Bachelor's Degree holders at 49.2\%. Few respondents had Master's Degree and $\mathrm{PhD}$ representing $(11.5 \%$ and $6.6 \%)$ respectively. 
4.3 Descriptive Statistics

Table 1: Levels of variables

\begin{tabular}{|c|c|c|c|c|}
\hline No. & Variables & Mean & Std. Dev. & Interpretation \\
\hline 1 & Physical Environment & 3.153 & 0.982 & Moderate \\
\hline 2 & Psychosocial Environment & 3.514 & 0.913 & High \\
\hline 3 & Work life Balances & 3.108 & 0.951 & Moderate \\
\hline 4 & Work Place Environment & $\mathbf{3 . 2 5 8}$ & $\mathbf{0 . 9 4 8}$ & Moderate \\
\hline 5 & Employee Performance & $\mathbf{3 . 0 7 1}$ & $\mathbf{1 . 1 0 9}$ & Moderate \\
\hline
\end{tabular}

Accord to table 1 all the variables show that the levels are moderate and with the exception of

Workplace Environment, which indicated High $($ mean $=3.51)$

Psychosocial environment, a construct of

\subsection{Correlation Analysis}

Table 2: Correlations Analysis of Variables

\begin{tabular}{|c|c|c|c|c|}
\hline Variables & $\begin{array}{c}\text { Employee } \\
\text { Performance }\end{array}$ & $\begin{array}{c}\text { Physical } \\
\text { environment }\end{array}$ & $\begin{array}{c}\text { Psychosocial } \\
\text { Environment }\end{array}$ & $\begin{array}{c}\text { Work life } \\
\text { Balances }\end{array}$ \\
\hline $\begin{array}{c}\text { Employee } \\
\text { Performance }\end{array}$ & 1 & $0.218^{*}$ & $0.221^{*}$ & 0.147 \\
\hline
\end{tabular}

*Significant at 0.05

According to (56), the effect size is low if the value of $r$ converges around 0.1, medium if $r$ is around 0.3 , and large if $r 0.5$ or above. From the correlation analysis in table 2 , it was indicated that the Pearson Correlation of 0.218 . The results showed there is a positive and significant relationship between physical environment and Employee performance $(r=.218, p<0.05)$. Table 2 also indicated that the Pearson Correlation of 0.221 . This therefore implies that the null hypothesis states: There is no significant relationship between physical environment and employee performance is reject and the alternative is accepted. There is a significant relationship between physical environment and employee performance in Fort Portal Referral Hospital

\subsection{Multiples Regression Analysis}

Table 3: Physical, Psychosocial and Work Life Balance on Employee Performance

\begin{tabular}{|c|c|c|c|c|c|c|}
\hline \multirow{2}{*}{\multicolumn{2}{|c|}{ Model }} & \multicolumn{2}{|c|}{$\begin{array}{l}\text { Unstandardized } \\
\text { Coefficients }\end{array}$} & \multirow{3}{*}{$\begin{array}{c}\begin{array}{c}\text { Standardized } \\
\text { Coefficients }\end{array} \\
\text { Beta } \\
\end{array}$} & \multirow[t]{2}{*}{$\mathbf{t}$} & \multirow[t]{2}{*}{ Sig. } \\
\hline & & $\boldsymbol{B}$ & Std. Error & & & \\
\hline & (Constant) & 0.834 & 0.554 & & 1.505 & .135 \\
\hline & $\begin{array}{c}\text { Physical } \\
\text { environment }\end{array}$ & 0.221 & 0.107 & 0.186 & 2.071 & $0.041^{*}$ \\
\hline & $\begin{array}{l}\text { Psychosocial } \\
\text { Environment }\end{array}$ & 0.252 & 0.103 & 0.219 & 2.446 & $0.016^{*}$ \\
\hline & $\begin{array}{l}\text { Work Life } \\
\text { Balance }\end{array}$ & 0.158 & 0.105 & 0.135 & 1.508 & 0.134 \\
\hline $\mathrm{R}$ & 0.338 & & & & & \\
\hline $\mathrm{R}^{2}$ & 0.114 & & & & & \\
\hline Adjusted $\mathrm{R}^{2}$ & 0.090 & & & & & \\
\hline $\mathrm{F}$ & 4.801 & & & & & \\
\hline $\begin{array}{l}\text { Durbin- } \\
\text { Watson }\end{array}$ & 2.041 & & & & & \\
\hline
\end{tabular}

"Significant at 0.05 
The results suggest a similarly positive and significant relationship between psychosocial environment and workers performance $(r=.221$, $p<0.05)$. This suggests that the null hypothesis states: There is no significant relationship between psychosocial environment and employee performance is rejecting and the alternative is accepted. Therefore, there is a significant relationship between psychosocial environment and employee performance in Fort Portal Referral Hospital.

Both results suggest that better physical workplace environment and better psychosocial environment could improve employees' performance and ultimately improve their productivity. The results on table 2 showed there is a positive relationship between work life balances and workers performance $(r=.147, p>0.05)$, however this relationship is not statistically significant at the conventional levels. This confirms that the null hypothesis stated: There is no significant relationship between work life balance and employee performance is accepted.

Table 3 indicates that the constructs of Workplace Environment, particularly physical and psychosocial environment, and work life balance have a significant positive effect on employee performance by causing a variance of $11 \%$ $(R 2=0.114, p<0.05)$. However only physical $(\beta=0.19$, $p<0.05)$ and psychosocial $(\beta=0.22, \quad p<0.05)$ environment are significant predictors. Psychosocial environment makes the biggest contribution, while work like balance is statistically insignificant. After comparing the $\mathrm{F}$ statistic and the Critical $F$ value (from the $F$ distribution table), the $F$ statistic $(F=4.80)$ is larger than critical $F$ value $(F 3,112 ; 0.05=2.70)$, confirming that the model as a whole is significant at a 5 percent significance level. The Durbin-Watson ( $d=2.04)$, which is between the two critical values of $1.5<d<2.5$ confirms that there is no first order linear auto-correlation in our multiple regression data. The insignificant effect of work life balance on employee performance could be explained by (57) who pointed out that the pursuit of work life balance by medical workers can at times undermine the workers quality of life by placing additional, often impracticable, expectations to their already stressful lives.

\subsection{CONCLUSION}

Performance among Health Care Providers at Fort Portal Referral Hospital is influenced by numerous aspects and elements. The study findings suggest that psychosocial and physical aspects were important in enhancing the performance of employees in the hospital. The study indicates that the levels of constructs of work environment where moderate (physical and work life balance), psychosocial environment which was high. In this study psychosocial environment proves to be the biggest indicator in influencing employee performance, while work life balance proved to be insignificant. Though the data for this study was collected before COVID-19 became a global pandemic, the emphasis on the work environment and particularly the physical work environment cannot be over stated especially in the health care sector. It is a matter of life and death (58).

The recommendation is there made the more emphasis should be place on the environment (physical and psychosocial work environments) that contribute to employee performance, this is due to the fact that in the long run they can even help enhance quality of life of the health care providers. In the immediate future they can guarantee the safety of the health care providers. This implies providing suitable working equipment and creating a conducive environment to help mitigate the high levels of stress the profession evokes especially in the face of the global COVID-19 pandemic. The work psychosocial work environment should be characterised by supportive leadership, team spirit, work design, work role and a positive organisational climate and culture. While the physical work environment should cater for quality protective clothing and equipment, conducive temperature, air quality, lighting and noise conditions that allows the health care workers focus better on their work. Though work life balance did not have a significant effect in this study, it is still advisable to consider its role in the success of any organisation $(36,8)$.

\subsection{CONFLICT OF INTEREST}

There is no conflict of interest in this present study. This research work is not a part of any other studies and it is our original work.

\subsection{REFERENCES}

1. Chapins A. Workplace and the performance of workers. Reston: USA. 1995.

2. Mike A. Visual workplace: How you see performance in the planet and in the office. International Journal of Financial Trade. 2010; 11(3): 250-260.

3. Shikdar AA. Identification of ergonomic issues that affect workers in oilrigs in desert environments. International Journal of Occupational Safety and Ergonomics. 2004; 10(2): 169-177.

4. Naharuddin N, Sadegi M. Factors of workplace environment that affect employee's 
performance: A case study of Miyazu Malaysia. International journal of independent research and studies. 2013; 2(2): 66-78.

5. Chandrasekar K. Workplace environment and its impact on organisational performance in public sector organisations. International journal of enterprise computing and business systems. 2011; 1(1): 1-19.

6. Leblebici D. Impact of workplace quality on employee's productivity: case study of a bank in Turkey. Journal of Business, Economics. 2012; 1(1): 38-49.

7. Taiwo AS. The influence of work environment on workers productivity: A case of selected oil and gas industry in Lagos, Nigeria. African journal of business management. 2010; 4(3): 299307.

8. Smith KT. Work-life balance perspectives of marketing professionals in generation Y. Services Marketing Quarterly. 2010; 31(4): 434-447.

9. Heath B. Effect of perceived work environment on employee's job behavior and Empirical investigation. Strategic Management Journal. 2006; 7(2): 217-31.

10. Becker F. Improving organisational performance by exploiting workplace flexibility. Journal of Faculty Management. 2002;1(2):154-162.

11. Kisubi J. Institutional Challenges in Inpatients Health Service Delivery in Regional Hospitals in Uganda. A case of Fort Portal Hospital (Doctoral dissertation, Uganda Management Institute).

12. Haynes BP. The Impact of office comfort on productivity. Journal of Facilities Management. 2008; 6 (1): 37-51.

13. Cunneen P. How to improve performance management. People Management. 2006; 12(1): 12.

14. Abdulla J, Baker S, Vlasic B. Environmental performance In a Banking Perspective. Journal on Finance and Banking. 2010; 33(1): 22-33.

15. Platt \& Sobotka. Psychological Management of Individual Performance. John Wiley \& Sons, Wales. 2010.

16. Kwizera M, Osunsan OK, Irau F, Wandiba A, Abiria P, Innocent B. Effect of Organizational Change on Employee Performance among selected Commercial Banks in Bujumbura, Burundi. East African Scholars Journal of Economics, Business and Management. 2019; 2(4): 225-234.

17. Sabir MS, Iqbal JJ, Rehman KU, Shah KA, Yameen M. Impact of corporate ethical vaulues on ethical leadership and employee performance. International Journal of Business and Social Science. 2012; 3(2): 163-171.

18. Tumwebaze E, Wandiba A, Osunsan OK, Kabasinguzi C. Negotiating Performance: Exploring the Effect of Negotiations as Conflict Resolution Strategy on Employee Performance in KCCA, Uganda. IAR Journal of Business Management. 2020; 1(3): 103-108.

19. Cummings M.J, Goldberg E, Mwaka S, Kabajaasi O, Vittinghoff E, Cattamanchi A, Davis JL. A complex intervention to improve implementation of World Health Organization guidelines for diagnosis of severe illness in low-income settings: a quasi- experimental study from Uganda. Implementation Science. 2017; 12(1): 126.

20. Lucas AO. Human resources for health in Africa: Human resources for health in Africa: Better training and firm national policies might manage the brain drain, BMJ. 2005; 331 (7524): 1037-1038.

21. Dieleman $M$, Harnmeijer JW. Improving health worker performance: in search of promising practices. Geneva: World Health Organization. 2006: 5-34.

22. Nzewi HN, Augustine A, Mohammed I, Godson 0. Physical work environment and employee performance in selected brewing firms in Anambra State. Nigeria Journal of Good Governance and Sustainable Development in Africa. 2018; 4: 131-145.

23. Amir F. Measuring the impact of office environment on performance level of employees: A case of private sector of Pakistan. In Proceedings of the 2nd International Conference of AGBA South Asia Chapter on Nurturing Innovation, Entrepreneurship, Investments and Public Private Partnership-in Global Environment, 2010; 247-264.

24. Temessek M. Expanding the psychosocial work environment: workplace norms and 34 workfamily. Conflict as Correlates of Stress and Health. 2009;3(1):71-88.

25. Vischer JC. The effects of the physical environment on job performance: towards a theoretical model of workspace stress. Stress and health: Journal of the International Society for the Investigation of Stress. 2007;23(3):175-184.

26. Rorong SV. The Impact of Physical Work Environment Toward Employee Performance At Pt. Bank Negara Indonesia Manado Regional Office. Jurnal EMBA: Jurnal Riset Ekonomi, Manajemen, Bisnis dan Akuntansi. 2016; 4(1): 441-450

27. Kurniawan H, Heryanto H. Effect of Work Discipline and Work Environment on Employee Performance with Work Motivation as an Intervening Variable in Department of Tourism, Youth and Sport of Padang District. Archives of Business Research. 2019; 7(7): 88-101.

28. Vischer JC. Towards an environmental psychology of workspace: how people are affected by environments for work. Architectural science review. 2008; 51(2): 97-108.

29. Rugulies R. What is a psychosocial work environment? Scandinavian Journal of Work, Environment \& Health. 2018; 45(1): 1-6.

30. Noe RA, Kodwani AD. Employee training and development, 7e. McGraw-Hill Education; 2018 Jul 21. 31. Warr P. Psychology at work. Penguin UK; 2002 Mar 28.

32. Sverke M. The importance of the psychosocial work environment for employee wellbeing and work motivation. Scandinavian journal of work, environment \& health. 2009; 35(4): 241-243.

33. Idris MA, Dollard MF, Tuckey MR. Psychosocial safety climate as a management tool for employee engagement and performance: A multilevel analysis. International Journal of Stress Management. 2015; 22(2): 183.

34. Jayaweera T. Impact of work environmental factors on job performance, mediating role of work motivation: A study of hotel sector in England. 
International journal of business and management. 2015; 10(3): 271.

35. Lazauskaite-Zabielske J, Urbanaviciute I, Balsiene RR. From psychosocial working environment to good performance: the role of work engagement. Baltic Journal of Management. 2018; 13 (2): 236-249. 36. McCarthy A, Cleveland JN, Hunter S, Darcy C, Grady G. Employee work-life balance outcomes in Ireland: a multilevel investigation of supervisory support and perceived organizational support. The International Journal of Human Resource Management. 2013; 24(6): 1257-1276.

37. Clark RB, Morgan BS. How is your work life/personal life balance? Strategy \& Leadership.2001; 29(5): 2

38. Hill EJ, Hawkins AJ, Ferris M, Weitzman M. Finding an extra day a week: The positive influence of perceived job flexibility on work and family life balance. Family relations. 2001; 50(1): 49-58.

39. Galinsky E, Bond JT, Friedman, DE. The role of employers in addressing the needs of employed parents. Journal of Social Issues. 1996; 52(3): 111136

40. Allan C, Loudoun R, Peetz, D. Influences on work/non-work conflict. Journal of Sociology. 2007; 43: 219-239

41. Tausig $\mathrm{M}$, Fenwick R. Unbinding time: Alternate work schedules and work-life balance. Journal of family and economic issues. 2001; 22(2): 101-119.

42. Donald H, Smythe L, McAra-Couper J. Creating a better work-life balance. New Zealand College of Midwives Journal. 2014:49.

43. Yadav RK, Dabhade N. Work life balance and job satisfaction among the working women of banking and education sector-A comparative study. International Letters of Social and Humanistic Sciences. 2014; 21:181-201.

44. Adame-Sánchez C, González-Cruz TF, Martínez-Fuentes C. Do firms implement work-life balance policies to benefit their workers or themselves? Journal of Business Research. 2016; 69(11): 5519-5523.

45. Johari J, Tan FY, Zulkarnain ZIT. Autonomy, workload, work-life balance and job performance among teachers. International Journal of Educational Management. 2018; 32 (1):107-120.

46. Beauregard TA, Henry LC. Making the link between work-life balance practices and organizational performance. Human resource management review. 2009; 19(1): 9-22.

47. Hughes J, Bozionelos N. Work-life balance as source of job dissatisfaction and withdrawal attitudes. Personnel Review. 2007; 36 (1): 145-154.

48. Kanwar YPS, Singh AK, Kodwani AD. Worklife balance and burnout as predictors of job satisfaction in the IT-ITES industry. Vision. 2009; 13(2): 1-12.

49. Krejcie RV, Morgan DW. Determining sample size for research activities. Educational and psychological measurement. 1970; 30(3): 607-610. 50. Choi JH, Beltran LO, Kim HS. Impacts of indoor daylight environments on patient average length of stay (ALOS) in a healthcare facility. Building and environment. 2012; 50: 65-75.
51. Boudrias JS, Desrumaux P, Gaudreau P, Nelson K, Brunet L, Savoie A. Modeling the experience of psychological health at work: The role of personal resources, social-organizational resources, and job demands. International Journal of Stress Management. 2011;18(4): 372.

52. McCoy JM. Work environments. Handbook of environmental psychology. 2002: 443-460.

53. Humphries M. Quantifying occupant comfort: Are combined indices of the indoor environment practicable? Building Research and Information. 2005; 33(4): 317-325.

54. Veitch JA, Charles KE, Newsham GR, Marquardt CJ, Geerts J. Workstation characteristics and environmental satisfaction in open-plan offices: COPE field findings. National Research Council Canada. 2004.

55. Amin ME.Social science research: Conception, methodology and analysis. Makerere University. 2005; pp 200-260

56. Cohen J. A power primer. Psychological bulletin. 1992 Jul;112(1):155.

57. Schwingshackl A. The fallacy of chasing after work-life balance. Frontiers in pediatrics. 2014; 2: 26. 58. Adams JG, Walls RM. Supporting the health care workforce during the COVID-19 global epidemic. Jama. 2020;323(15):1439-40 